Archives

9| 1992

Varia

\title{
Les juifs et le droit à la différence : entre l'idéal de l'état-nation et le nationalisme des minorités
}

\author{
Judith Friedlander
}

\section{(2) OpenEdition}

Journals

Édition électronique

URL : http://journals.openedition.org/ccrh/2811

DOI : $10.4000 /$ ccrh.2811

ISSN : 1760-7906

Éditeur

Centre de recherches historiques - EHESS

Édition imprimée

Date de publication : 15 avril 1992

ISSN : 0990-9141

Référence électronique

Judith Friedlander, « Les juifs et le droit à la différence : entre l'idéal de l'état-nation et le nationalisme des minorités », Les Cahiers du Centre de Recherches Historiques [En ligne], 9 | 1992, mis en ligne le 18 mars 2009, consulté le 19 avril 2019. URL : http://journals.openedition.org/ccrh/2811 ; DOI : 10.4000/ ccrh. 2811

Ce document a été généré automatiquement le 19 avril 2019

Article L.111-1 du Code de la propriété intellectuelle. 


\title{
Les juifs et le droit à la différence : entre l'idéal de l'état-nation et le nationalisme des minorités
}

\author{
Judith Friedlander
}

\section{La contestation de l'idéal français de l'état-nation par les intellectuels juifs de la génération de 1968}

\author{
La même volonté libératrice, assimilatrice et \\ ethnocidaire qui a détruit les provinces françaises, \\ réduit leur culture à un folklore, fait de leurs \\ langues un vice honteux, a également proposé aux \\ juifs français un marché que ceux-ci, vulnérables \\ comme ils l'étaient, ne pouvaient évidemment \\ qu'accepter : l'émancipation au prix des \\ dimensions nationalistes de leur existence \\ collective. \\ Richard Marienstras ${ }^{1}$
}

Au printemps 1967, quelques semaines avant la Guerre des Six jours, une douzaine d'intellectuels de gauche firent paraître un manifeste dans plusieurs journaux français. Rédigé par Richard Marienstras, professeur de littérature anglaise et spécialiste de Shakespeare, le texte commençait ainsi :

Les récents événements du Moyen-Orient ont dévoilé le malaise qui existait parmi les juifs de gauche en France. Indifférents à la religion, ne souhaitant pas émigrer en Israël, se sentant pleinement des citoyens de leur pays, ils ont, pour la plupart, tenu à se réaffirmer comme juifs malgré la diversité de leurs options. Cela a provoqué la surprise ${ }^{2}$.

2 Le Manifeste déclarait que les juifs partageant les mêmes opinions devaient se rassembler et définir leur position en tant que juifs face à la gauche qui ne les comprenait pas, 
l'establishment juif français pour qui les Juifs n'avaient à se déterminer que par rapport à la synagogue et au sionisme et enfin, face à Israël qui avait réduit les expressions du nationalisme juif au modèle occidental de l'État-nation. Contestant les thèses sionistes d'après lesquelles Israël devait être le centre de référence pour les Juifs de la diaspora, le manifeste rappelait la longue histoire de la diaspora juive sur plus de 2.000 ans au cours desquels des communautés installées en Europe, en Afrique du Nord et en Asie Mineure, avaient forgé la plupart des traditions religieuses et laïques aujourd'hui considérées comme juives. Cent cinquante personnes environ répondirent à l'appel et constituèrent le Cercle Gaston Crémieux, rattachant ainsi leur projet à celui d'un juif socialiste du XIX siècle, militant politique, qui fut exécuté quelques mois après la chute de la Commune de Paris. En prenant ce nom, le groupe affirma nettement son opposition à l'establishment juif français qui célébrait fréquemment la mémoire d'un autre Crémieux, son cousin Adolphe, fondateur de l'Alliance Israélite Universelle et auteur d'un décret qui reconnaissait les juifs algériens comme des citoyens français. Tandis qu'un des Crémieux défendait les intérêts des juifs en s'adaptant au système, l'autre risquait sa vie pour faire advenir un changement politique radical. Avocat, journaliste et poète, Gaston Crémieux participa au mouvement révolutionnaire qui se développait en France pendant les dernières années du Second Empire. Emprisonné en raison de ses activités politiques, il fut par la suite libéré par des représentants de la Révolution républicaine en septembre 1870 et continua à jouer un rôle majeur dans le Midi où il aida à la création de la Ligue radicale du Midi; il devint président de la commission qui représentait le département des Bouches-du-Rhône.

3 En mars 1871, quand les socialistes s'emparèrent de la capitale, Gaston Crémieux proclama la solidarité du peuple marseillais avec les Communards. La Commune de Paris ne dura que deux mois. Avec le retour des forces de l'ordre, le juif radical fut arrêté et exécuté en novembre de la même année. Quelqu'un aurait-il pu le sauver ? Si l'on en croit la notice biographique du Cercle, le prisonnier avait espéré que son cousin bien placé tenterait de le faire mais ce ne fut apparemment pas le cas ${ }^{3}$.

4 Le Cercle était en prise directe sur l'histoire de France bien plus que par son nom. Utilisant l'analyse de son fondateur Richard Marienstras, il cerna les problèmes qu'avaient connus les juifs laïcs dans la France contemporaine dans la définition de leur identité, jusqu'aux journées révolutionnaires et jusqu'aux circonstances politiques qui conduisirent à la création du Consistoire central (assemblée rabbinique) par Napoléon. Comme l'expliquait Marienstras dans son article précurseur, Les juifs de la diaspora ou la vocation minoritaire, pendant cette période, les juifs furent contraints de renoncer à leur identité « nationale » pour gagner leur émancipation politique ${ }^{4}$.

$5 \quad$ S'ils voulaient bénéficier des droits de citoyens, les juifs devaient s'assimiler et devenir "Français de confession mosaïque », membres d'une société culturellement homogène fréquentant un lieu de prière juif. Ils gagnaient une liberté religieuse mais perdaient la possibilité de développer leur autonomie nationale. En d'autres termes, ils pouvaient fréquenter la synagogue, comme les catholiques et les protestants français fréquentaient leurs églises, mais ils devaient devenir membres de la nation française : parler la même langue et s'identifier au même héritage culturel. Plus de deux cent ans plus tard, le Cercle contestait la légitimité du contrat et invitait la France à abandonner cette stipulation du XVIII ${ }^{e}$ siècle qui voulait qu'il n'y eût qu'une « seule nation » à l'intérieur de l'État. 
6 Après une interruption de ses activités en mai 1968, le Cercle reprit ses réunions en 1973. A cette époque, les membres déclarèrent qu'ils représentaient les juifs bien plus encore qu'auparavant :

Les raisons d'être du Cercle paraissent aujourd'hui plus valables que jamais, et son audience potentielle plus large : car il se confirme que le judaïsme officiel, polarisé par la synagogue ou le sionisme, a perdu (ou n'a jamais connu), l'audience des jeunes juifs qui, très visiblement, attendent un projet qui leur permettrait de se redécouvrir ou de s'affirmer hors de ces options ${ }^{5}$.

7 Le Cercle considérait que les jeunes juifs auraient de nouvelles options dès lors que le nationalisme minoritaire se développerait en France, comme il avait pu le faire en Europe de l'Est pendant l'entre-deux-guerres. Les jeunes juifs devaient s'informer sur les mouvements culturels et politiques qui avaient fleuri à Vilna, Varsovie ou ailleurs en Europe de l'Est avant 1939. Marienstras, s'inspirant du Bund ${ }^{6}$ et de l'oeuvre de l'historien juif Simon Dubnow, théoricien en honneur dans la diaspora juive, ne proposait pas un retour nostalgique au passé, mais la recherche sérieuse de modèles qui pourraient servir les intérêts des groupes ethniques composant la diaspora d'aujourd'hui :

On peut, plus concrètement, se demander: que faire, aujourd'hui, en France? Quelles orientations - en plus de celles qui existent déjà-donner à l'action culturelle? Quel doit être le rôle des institutions communautaires? Les orientations peuvent être indiquées brièvement : explorer le passé juif sous toutes ses formes et à travers toutes ses traditions: sépharade et ashkenase, yiddish, ladino, hébraïque et araméenne, religieuse et laïque, mystique ou révolutionnaire, bundiste ou biblique, cela devrait s'accompagner d'un effort renouvelé pour enseigner les diverses langues juives - et non exclusivement l'hébreu - mais aussi, pour ceux qui ne pourraient les apprendre, d'un programme systématique de traduction.

A côté de cela, qui concerne la «reprise en main» de l'héritage culturel, on pourrait encourager les études originales, de niveau universitaire et populaire, et particulièrement les études historiques : il est temps que l'historiographie juive en France fasse effort pour sortir de la conception providentielle ou finaliste de l'histoire juive, et qu'elle utilise des méthodes modernes avec larigueur scientifique désirable?.

8 Marienstras ouvrait ainsi un débat auquel beaucoup se joignirent bientôt, dont Albert Memmi qui avait déjà écrit deux livres sur la question juive ${ }^{8}$. Reprenant la fameuse analyse de Sartre dans ses Réflexions sur la question juive ${ }^{9}$, le philosophe d'origine tunisienne exprimait sa surprise qu'on puisse vouloir rester juif en France et développer une culture différente. Se comporter de la sorte, c'était accepter l'oppression d'une identité définie par d'autres. Memmi déclarait que le monde moderne avait rejeté la religion et ne proposait aux juifs qu'une seule voie pour s'affirmer en tant que tels: devenir citoyens d'un État-nation juif. Même si l'État d'Israël n'existait pas encore quand Sartre écrivait Réflexions sur la question juive, il existait aujourd'hui, apportant une heureuse conclusion à la question juive qui n'était pour Memmi l'objet que d'un intérêt académique. Ayant librement choisi d'embrasser la culture et la nationalité françaises, Memmi se préoccupait peu de vivre authentiquement en tant que juif. Sa décision, ajoutait-il, n'avait provoqué en lui aucun sentiment de perte d'identité ${ }^{10}$.

Pour entrer dans le vif du sujet, il nous faut faire un retour en arrière et nous intéresser à quelques questions qui permettent de cerner le débat. Commençons par un bref historique de la question de l'État-nation et du nationalisme des minorités en rapport avec la question juive. Bien que j'aie en premier lieu exposé la position du Cercle Gaston Crémieux, je souhaite m'intéresser à un aspect du problème que les porte-paroles du 
Groupe ont rarement abordé, à savoir l'impact des idées d'Europe occidentale concernant la culture sur ceux qui ont créé l'idée du nationalisme des minorités au tournant du siècle dans les Empires austro-hongrois et russe, et qui ont inspiré, bien plus tard, l'idéologie des intellectuels juifs français de la génération de 1968.

Quand les juifs progressistes d'Europe de l'Est ont commencé à quitter le judaïsme orthodoxe, dans les dernières décennies $\mathrm{du} \mathrm{xIX}^{\mathrm{e}}$ siècle, et à se reconnaître comme membres d'une minorité nationale juive, ils n'ont fait que traduire en hébreu et yiddish des idéaux d'Europe occidentale, intégrant ce faisant des aspects de cette philosophie qui mit un terme à la diversité culturelle en France. Célébrant l'humanisme des Lumières en France, ils prenaient modèle sur des philosophes ou des artistes qui vivaient dans les États-nations ou étaient influencés par l'Ouest. D'une manière générale, les mouvements littéraires en France, en Allemagne et Russie, déterminaient les critères universels que les artistes juifs utilisaient pour évaluer la qualité de leurs productions. Au cours du développement de leurs traditions laïques, les juifs se sont plutôt conformés aux idées et aux valeurs des États-nations d'Europe de l'Ouest, au détriment de leur spécificité culturelle.

\section{Les origines et l'évolution du débat : État-nation ou nationalisme des minorités?}

11 Les historiens font souvent remonter l'idée de nation au moins au Moyen Age. Toutefois, le nationalisme moderne date d'une période beaucoup plus récente. Il a pris forme en Europe de l'Ouest aux XVII et XVIII siècles dans les débats politiques des philosophes qui se demandaient s'il était sage de créer des États démocratiques bourgeois. Appréciant tout l'intérêt qu'il y avait à tirer parti des attachements ethniques, des théoriciens progressistes avancèrent que les gens éprouveraient un sentiment plus grand de patriotisme s'ils pouvaient s'identifier à la culture et à l'héritage de l'État. Jean-Jacques Rousseau fut sans doute le premier à développer une théorie pratique permettant de créer des citoyens patriotes dans un État-nation démocratique. Suivant la description de la cité-état idéale faite par Platon, Rousseau commença par s'intéresser à l'éducation des enfants mais il avait un projet plus ambitieux: développer un enseignement cohérent pour des individus provenant d'horizons culturels très variés et vivant dispersés sur un vaste territoire. Pour disposer de citoyens loyaux dans chaque coin du pays, partageant des intérêts et des buts communs, l'État avait besoin de former ses jeunes à s'identifier à une histoire unique et à un seul ensemble de traditions ${ }^{11}$.

D'autres voix se joignirent bientôt à la sienne. La démocratie exigeait l'uniformité culturelle : «Une seule nation dans un seul État ». Avant de légiférer que tous les hommes ont été créés égaux, tous devaient devenir identiques. Sur la base de ce principe, les progressistes ont proposé une politique d'émancipation des juifs. En 1791, le comte Stanislas de Clermont-Tonnerre fit sa fameuse déclaration pour la défense des juifs en ces termes:

Il faut tout refuser aux juifs en tant que nation et tout leur accorder en tant qu'individus ; il faut qu'ils ne fassent dans l'État ni un groupe politique ni un ordre : il faut qu'ils soient individuellement citoyens ${ }^{12}$.

13 A la fin du XVIII ${ }^{e}$ siècle et au début du XIX ${ }^{e}$ siècle, des juifs éclairés comprirent les limites de cette émancipation, mais ils finirent par en accepter les termes. Ils acceptèrent de faire 
un compromis, de renoncer à leur autonomie culturelle collective en échange de la liberté politique individuelle. Alors que la diversité - culturelle, socio-économique et politique des communautés juives en France était considérable, certaines étant favorables à l'émancipation, d'autres s'y opposant farouchement, la Révolution française n'offrit pas le choix aux juifs. Ils devinrent des «Français de confession mosaïque », et acceptèrent, pour la plupart, de renoncer à nombre de leurs traditions pour se conformer au modèle national ${ }^{13}$.

Les Lumières, dans leur progression vers l'Est au début du XIX ${ }^{e}$ siècle, offrirent des promesses de liberté par le biais de l'assimilation. Ici aussi, de nombreux juifs se tournèrent vers l'avenir en apprenant le russe, le polonais et l'allemand, en élevant leurs enfants dans les traditions de la société élargie, attendant patiemment l'émancipation pour rejoindre la Russie tsariste et l'Empire austro-hongrois. Vers le milieu du XIX siècle, de violentes vagues de nationalisme balayèrent l'Europe, offrant aux juifs éclairés de l'Est un nouveau moyen de s'intégrer au monde moderne. Certains restèrent des Européens partisans de l'assimilation, d'autres devinrent des nationalistes hébreux.

Contrairement aux partisans de l'assimilation qui essayèrent de devenir des Russes ou des Autrichiens partageant la foi de Moïse, les nationalistes hébreux favorisèrent le développement d'une culture juive laïque, constituant une menace sérieuse pour les communautés religieuses dans ces pays. Il est vrai que de nombreux nationalistes hébreux restèrent attachés au judaïsme, ce que l'on oublie souvent dans la littérature, mais ils insistaient aussi sur l'importance d'une définition des traditions juives hors de la synagogue, laissant ainsi se développer l'idée qu'on pouvait être un juif non-pratiquant. Vers la fin du siècle, le nationalisme hébreu était devenu le sionisme et des mouvements yiddish étaient nés, voués à l'instauration de cultures juives laïques dans la diaspora.

Il est facile de voir comment les juifs ont changé en s'adaptant aux traditions nationales françaises, allemandes ou russes, mais le processus est moins clair en ce qui concerne les mouvements juifs. Cependant, à y regarder de près, nous constatons qu'eux aussi ont épousé les idéaux de l'Europe de l'Ouest concernant les éléments d'une culture nationale. Même des sociaux-démocrates comme les Bundistes, hostiles au nationalisme territorial, partageaient des points de vue semblables sur la nécessité de développer leurs propres traditions culturelles.

17 En 1897 à Vilna, un groupe d'intellectuels et d'ouvriers juifs socialistes fondèrent l'Union des Travailleurs juifs de Lithuanie, Pologne et Russie. Ils donnèrent à leur parti l'appellation plus brève de Bund (Union). Influencés par le populisme et le socialisme russes, ils contribuèrent à créer en 1898 le Parti Social Démocrate Russe, tout en restant attachés à leur identité politique et culturelle de juifs. En 1912, quand les Bolcheviques et les Menchéviques se séparèrent, les Bundistes se rangèrent aux côtés des derniers. Pendant les premières années du parti, il y eut un certain nombre de glissements idéologiques entre les Européens partisans de l'assimilation et les nationalistes yiddish, mais vers 1917, les Bundistes étaient relativement unis dans leur demande d'autonomie nationale-culturelle. Leur programme s'efforçait de combiner la vision socialiste internationaliste et la spécificité culturelle.

Vers la fin de la Première Guerre mondiale, le Bund avait élaboré des positions puissantes et bien articulées contre le sionisme et l'orthodoxie religieuse. Hostile à l'enseignement de l'hébreu, le parti encourageait l'observance des fêtes traditionnelles dans des rencontres non-religieuses. Ainsi, il continuait à célébrer Pâques comme une fête de 
libération de l'esclavage. Plus important encore, le Bund oeuvra au développement de l'enseignement de l'histoire juive et à la création d'une culture ouvrière laïque fondée sur la langue des masses, le yiddish ${ }^{14}$.

Le Bund fut prospère en Europe de l'Est pendant les années 20 et 30 en même temps que d'autres mouvements nationaux juifs, de tendance sioniste ou pro-diaspora, certains préférant l'hébreu, d'autres le yiddish. Pendant ce temps, Vilna était devenue une ville polonaise ${ }^{15}$, mais elle restait un centre important du Bund et du sionisme socialiste. Des juifs mirent sur pied des écoles primaires pour l'enseignement de l'hébreu et du yiddish, des lycées et des écoles normales. Puis, en 1925, des intellectuels yiddishisants dont beaucoup étaient membres du Bund, créèrent YIVO, l'Institut pour la recherche juive à Vilna. Jusqu'à la Deuxième Guerre mondiale, époque à laquelle l'Institut quitta la Pologne et transfera son siège à New York, YIVO joua un rôle majeur dans la définition des paramètres de la nouvelle tradition en yiddish. Parmi ses nombreux projets, YIVO envoya dans le pays des étudiants en anthropologie et folklore étudier la culture des juifs du shtetl, avant que ce genre de vie ne disparaisse complètement ${ }^{16}$.

De nombreux écrivains et auteurs dramatiques se sont inspirés de thèmes juifs, développant leur art dans un engagement politique envers la culture yiddish. Le Dybbuk, la pièce de $\mathrm{S}$. Ansky, est un très bon exemple du type d'ouvrage qu'on aimait lire à cette époque. Pionnier dans le domaine du folklore juif et socialiste, il en écrivit le scénario pour la mise en scène après avoir dirigé une mission juive ethnographique en Ukraine, dans les villages de Volhynia et Podolia (1911-1914). Ansky écrivit d'abord sa pièce en russe puis la traduisit en yiddish, y introduisant des changements qui lui avaient été suggérés par le directeur du théâtre d'art de Moscou, Constantin Stanislavsky.

21 Proposant une interprétation socialiste de la condition des juifs du shtetl, Le Dybbuk décrit le destin de Khanan, pauvre étudiant de la yéchiva tombé amoureux de la fille d'un homme riche. Désespérant d'empêcher sa Léa d'en épouser un autre, Khanan recourt aux pouvoirs magiques de la Kabbale et de l'envoûtement. Il meurt au cours de l'opération, emportant avec lui l'âme de sa bien-aimée. Ce que la vie lui refuse pour des raisons sociales, il s'en empare par la mort ${ }^{17}$.

Des artistes comme Ansky rejetaient pour eux-mêmes le shtetl, lui préférant le monde plus large, plus cosmopolite des intellectuels russes; cependant nombre d'entre eux revinrent au yiddish afin de préserver pour la postérité les coutumes de leur peuple. En rapportant les traditions des juifs qui vivaient encore dans ces villes reculées, les partisans de la culture yiddish faisaient naître l'espoir d'un futur libéré, un futur qui affranchirait les pauvres de la loi qu'elle soit juive ou non juive. Un tel rêve exigeait évidemment que les juifs s'émancipent par rapport au judaïsme orthodoxe et qu'ils s'assimilent à la culture européenne.

D'autres utilisaient le yiddish comme un moyen de participer aux mouvements littéraires que dominaient les oeuvres d'éminents écrivains russes, français et allemands. Passant en revue l'histoire des lettres yiddish, Benjamin Harshav résume leurs contributions de la façon suivante :

Sur une brève période, des douzaines d'écrivains importants créèrent une littérature conforme aux critères européens, passant doucement, par le biais de la parodie bouffonne, des Lumières rationalistes au Réalisme, au Naturalisme et à l'Impressionisme psychologique, puis glissant, après avoir rompu avec ces modèles européens conventionnels, vers la tendance littéraire générale de l'Expressionisme et du Modernisme. 
Ceci devint possible grâce à la laïcisation des masses juives et à leur tendance à se tourner vers le monde de la culture et de la politique modernes dans les langues qu'elles connaissaient $^{18}$. ils y joignirent quatorze traités séparés où ils énuméraient les droits des peuples minoritaires qui vivaient désormais dans ces nouveaux États. Utilisant la Pologne comme un exemple-type, les Alliés rédigèrent les autres traités sur le modèle établi pour ce pays. Le traité des Minorités Polonaises définissait qui était un citoyen (articles 7 et 8), et donnait des instructions précises au Gouvernement sur la façon de traiter ceux qui tombaient sous sa juridiction : défendre la vie et la liberté de chacun « sans distinction de naissance, de nationalité, de langue, de race ou de religion» (article 2). En d'autres termes, tout en reconnaissant à la Pologne la souveraineté sur ses territoires, les Alliés ne lui accordaient pas une totale souveraineté. Les minorités officiellement reconnues jouissaient de la protection de la Société des Nations, protection dont ne bénéficiaient pas des groupes ethniques comparables vivant à l'Ouest. Ainsi, autour de Vilna, où vivaient des communautés assez nombreuses d'Ukrainiens, de Biélorusses et de juifs, le Gouvernement devait créer des écoles primaires dispensant leur enseignement dans les langues de ces peuples (article 9). De même, les hôpitaux, ainsi que tous les services publics, devaient disposer d'un personnel parlant les langues appropriées. le Traité comprenait aussi une série de réglementations interdisant à la Pologne d'adopter une législation susceptible de ne pas respecter le Sabbath juif et certaines pratiques alimentaires. Ainsi, les élections ne pourraient se dérouler le samedi.

D'importants groupes de pression juifs, anglais, français et américains, usèrent fortement de leur influence lors de la Conférence de Paix de Paris pour garantir la protection individuelle et religieuse aux juifs d'Europe de l'Est, comme cela se faisait à l'Ouest. D'autres furent plus ambitieux : ils espéraient obtenir une représentation séparée pour les juifs d'Europe de l'Est à la Société des nations. Si l'organisation internationale ne leur attribua pas de siège, les juifs d'Europe de l'Est gagnèrent néanmoins le droit de préserver leur identité collective, droit qu'ils n'avaient jamais possédé à l'Ouest. 
28 Même les États-Unis, réputés pour ouvrir leurs frontières aux peuples du monde entier, décourageaient leurs citoyens de conserver leur identité culturelle. Le système d'enseignement public apprenait aux nouveaux venus à verser leur passé dans le grand pot commun et les immigrants apprenaient rapidement à se sentir mal à l'aise du fait de leurs habitudes "étrangères ". Mais quand Woodrow Wilson, à son retour de Paris, fit campagne en faveur des Traités des Minorités, il donna l'impression que les Américains avaient toujours favorisé la diversité ethnique :

Mes chers concitoyens, nous autres Américains, parmi tous les peuples du monde, devrions être capables de comprendre les enjeux de ce traité, sans que quiconque ait besoin de nous l'expliquer; car nous sommes constitués de tous les peuples du monde. J'ose dire que dans cette assistance, il se trouve des représentants de presque tous les peuples concernés par ce traité.

Vous n'avez pas besoin que je vous explique les ambitions nationales, les aspirations nationales. Vous avez grandi avec elles; vous les avez apprises depuis votre enfance et ce sont ces aspirations que nous avons cherché à réaliser pour donner un avenir à ce grand traité ${ }^{19}$.

Proposant une analyse plus directe des traités protégeant les droits des minorités, l'historien diplomate anglais, H.W.V. Temperly, expliquait les raisons pour lesquelles les Alliés ne soutenaient le pluralisme culturel que dans les états nouvellement créés, tout en continuant à avoir, chez eux, des pratiques discriminatoires vis à vis des groupes ethniques. Dans son étude volumineuse sur la Conférence de Paix de Paris, publiée en 1921, Temperly faisait les observations suivantes :

A cette époque, on objecta en Pologne et ailleurs qu'il était difficile de justifier des procédures qui soumettaient l'état polonais, une puissance alliée et amie, à un contrôle odieux de ses affaires intérieures, contrôle auquel l'Allemagne elle-même était soustraite. La vérité est en fait la suivante. Si le principe de ces traités avait été appliqué à l'Allemagne, il aurait éventuellement été très difficile de refuser qu'il soit universellement appliqué à tous les États existants. Mais une telle disposition, comme nous l'avons vu, aurait constitué une innovation sans précédent. Quiconque a une connaissance de l'état de l'opinion en cette matière, sait fort bien qu'une telle proposition n'aurait eu aucune chance d'être acceptée ou qu'il aurait été peu avisé de l'imposer. Si ce principe avait été adopté, il aurait pu être interprété de telle sorte qu'il aurait permis aux Noirs des États du Sud des États-Unis de se mettre sous la protection de la Société des Nations. Cela aurait également été valable pour les Basques d'Espagne, les Gallois et les Irlandais ${ }^{20}$.

Nous savons que la Pologne ne respectait pas les droits de ses minorités ethniques depuis très longtemps, si elle l'avait jamais fait. S'opposant avec véhémence à l'ingérence de la Société des Nations dans leurs affaires intérieures, les Polonais refusèrent souvent d'appliquer le traité. Les juifs en souffrirent beaucoup. Vers les années 30, avec le développement des groupes fascistes dans le pays, le gouvernement fit souvent preuve à leur encontre de discrimination ${ }^{21}$.

31 Cependant, les nationalistes juifs profitèrent du soutien de l'Ouest et développèrent avec enthousiasme leurs spécificités culturelles. Si l'on considère uniquement les activités journalistiques en yiddish, vers 1926, vingt quotidiens paraissaient dans cette langue en Pologne, soixante hebdomadaires et trois mensuels. Onze ans plus tard (1937), il y avait vingt-sept quotidiens, cent hebdomadaires et quatre-vingt-cinq mensuels ${ }^{22}$.

32 En somme, l'idée de constituer des cultures nationales juives prit forme au XIX ${ }^{e}$ siècle. Mais ce ne fut qu'après la Première Guerre mondiale, quand les minorités nationales furent reconnues par les traités comme un peuple national, que les juifs commencèrent à 
développer largement leurs traditions laïques. Il est vrai que les Alliés favorisaient la diversité culturelle à l'Est pour des raisons d'intérêt propre, mais les nationalistes juifs accueillirent favorablement les décisions obtenues à la Conférence de Paix de Paris. Les sionistes comme les partisans du yiddish, ceux qui étaient en quête d'une patrie juive et ceux qui s'associaient à la lutte internationale des classes ouvrières en tant que socialistes d'identité juive, tous ouvrirent des écoles et autres centres culturels pour promouvoir des traditions juives laïques. L'origine de ce qui se produisit dans les années 20 et 30, remonte à une centaine d'années mais l'intensité de l'activité au théâtre, dans la presse, dans l'éducation et dans l'arène politique, était le reflet de la victoire du nationalisme moderne qui suivit la guerre, d'une idéologie qui fit de l'ethnicité le centre de son projet politique.

En devenant un peuple national, les juifs transformèrent leur culture, car «il n'y a pas que la politique, mais aussi la culture qui provoque des changements importants dans la diffusion de la doctrine nationaliste $»^{23}$. Il me semble que les changements qui sont intervenus ne furent pas arbitraires. Ils se sont conformés à un ensemble d'affirmations développées au XVIII ${ }^{\mathrm{e}}$ siècle en France et en Allemagne sur ce qu'était une culture nationale bona fide.

Avec le temps, les idéologies nationalistes ont avancé et reculé en Europe, au service de mouvements politiques et sociaux très divers et s'adaptant à des contextes géopolitiques différents. Aujourd'hui, depuis la fin des années 60 , nous en voyons se développer en France une version qui s'inspire des idéaux de certains juifs d'Europe de l'Est, en grande partie grâce aux efforts du Cercle Gaston Crémieux. En reprochant à la France de soutenir le principe d'une seule nation dans un seul État, des membres du groupe se sont appuyés sur le programme du Bund qui réclamait l'autonomie culturelle dans un État multinational.

Mais quel type de culture les yiddishistes cherchaient-ils à développer pour les juifs autonomes? Une culture utilisant la langue des masses juives pour produire une littérature qui soit conforme aux critères fixés par les artistes attachés aux valeurs humanistes de l'Europe de l'Ouest. C'est pourquoi, de façon paradoxale, les intellectuels français en promouvant les idéaux des nationalistes yiddish et en s'efforçant d'instaurer en France leurs propres traditions juives laïques, sont retournés à la vision universaliste de la culture, exprimée par les philosophes des Lumières qui ont contribué à justifier la création des États-nations européens.

\section{NOTES}

1. Richard MARIENSTRAS, "Les juifs de la diaspora ou la vocation minoritaire", Les Temps modernes, Août-septembre 1973 ; réédité dans Richard MARIENSTRAS, Être un peuple en diaspora, Paris, Maspéro, 1975, p. 72. Claude Lanzmann, Pierre Vidal-Naquet, Léon Poliakov et Rita Thalman signèrent aussi ce manifeste.

2. Le Manifeste, libelle diffusé par le Cercle Gaston Crémieux.

3. Texte ronéotypé diffusé par le cercle Gaston Crémieux dans les années 1970.

4. «Les juifs de la diaspora... », op. cit. 
5. Bulletin ronéotypé distribué par le Cercle Gaston Crémieux pendant les années 1970.

6. Voir plus loin, page 104.

7. R. MARIENSTRAS. "Les grandes lignes d'une politique culturelle de la diaspora », dans Être un peuple en diaspora, op. cit., p. 201.

8. Albert MEMMI, Portrait d'un Juif, Paris, Gallimard, 1962 et La Libération du Juif, Paris, Payot, 1966.

9. Jean-Paul SARTRE, Réflexions sur la question juive, Paris, Gallimard, 1946.

10. Albert Memmi fit ces commentaires lors d'une table ronde sur l'identité juive organisée lors des "Journées de la culture yiddish", avec le soutien, entre autres, des membres du Cercle Gaston Crémieux, et qui se sont tenues au Centre Georges Pompidou à Paris en novembre 1978.

11. Voir par exemple, Jean-Jacques ROUSSEAU, Traité sur le Gouvernement de Pologne, chapitre IV consacré à l'éducation.

12. Comte Stanislas de Clermont-Tonnerre, cité dans Léon POLIAKOV, Histoire de l'antisémitisme, Paris, Calmann-Lévy, 1968, tome III. De Voltaire à Wagner, p. 234.

13. Léon POLIAKOV, Ibid., p. 235.

14. En ce qui concerne le Bund, voir J.J. TOBIAS, The Jewish Bund in Russia From its Origins to 1905, Stanford, Stanford University Press; Jonathan FRANKEL, Prophecy and Politics, Cambridge University Press, 1981 : Rachel ERTEL, Le shtetl, Paris, Payot, 1982 ; Nathan WEINSTOCK. Le Pain de misère, histoire du mouvement ouvrier juif en Europe, 3 vol., Paris. Ed. La Découverte, 1984, 1986.

15. Vilna, capitale de la province lithuanienne de la Russie tsariste, fut rattachée à la nouvelle République de Pologne après la Première Guerre mondiale. Pendant les premiers jours de la Seconde Guerre mondiale, quand l'Union soviétique occupa la partie orientale de la Pologne, Staline détacha cette ancienne cité de la Pologne et la rattacha à la Lithuanie en même temps qu'il absorbait l'État balte ainsi que la Latvie et l'Estonie, dans les nouvelles frontières de l'URSS. Quand Vilna faisait partie de la Pologne, les Polonais l'appelaient Wilno. Puis, quand la cité devint partie de la République soviétique de Lithuanie, on l'appela de son nom lithuanien de Vilnius. Je continue à utiliser la forme russe parce que mon champ d'étude inclut des juifs qui se sont identifiés à l'histoire et aux traditions de la cité telle qu'elle existait avant la Première Guerre mondiale. Même ceux qui vivaient à Wilno pendant l'entre-deux-guerres, se considéraient le plus souvent comme des juifs russes et non polonais et continuaient de parler de Vilna.

16. Voir par exemple J.L. CAHAN ed., Jewish Folklore, Wilno, Publ. de l'Institut scientifique yiddish, 1938, Philological Series, vol. V et Yivo's Bibliographical Listings for 1925-41, New York, Yivo, 1943.

17. S. ANSKY, The Dybbuk, traduit en anglais du yiddish par H. Alsberg et W. Katzin, New York, Liveright, 1971.

18. Benjamin HARSHAV, The Meaning of Yiddish, Berkeley, University of California Press, 1990, p. 84 .

19. Woodrow WILSON, The Hope of The World: Messages and Addresses by the President, July 10, 1919 - Décember 9, 1919, New York, Harper and Brothers, 1920, p. 76.

20. Harold W.V. TEMPERLY, A History of the Peace Conference of Paris, London, H. Frownde and Holder and Stoughton, 1921, vol. V, Economic Reconstruction and Protection of Minorities, pp. 134-35.

21. Voir par exemple, Celia HELLER, On the Edge of Destruction : Jews in Poland between the Two Wars, New York, Columbia University Press, 1977 ; Rachel ERTEL, Le Shtetl, op. cit.

22. Richard MARIENSTRAS, Être un peuple en diaspora, op. cit., p. 154.

23. F.M. BARNARD, "National Culture and Political Legitimacy : Herder and Rousseau ", Journal of the History of Ideas, vol. XLIV, $\mathrm{n}^{\circ}$ 2, April-June, 1983, p. 251. 


\section{AUTEUR}

\section{JUDITH FRIEDLANDER}

Judith FRIEDLANDER est professeur d'anthropologie et dirige la Faculté des Sciences sociales à Hunter College, City University of New York. Elle a été directeur d'études associé à l'EHESS en 1990-91. 